\title{
Who is discharged to intermediate care facilities? An Italian study on the population of Udine
}

\author{
Francesca Valent, ${ }^{1}$ Angela Panzera ${ }^{2}$ \\ ${ }^{1}$ SOC Istituto di Igiene ed Epidemiologia Clinica; and ${ }^{2}$ Distretto di Udine, Azienda Sanitaria Universitaria Integrata di Udine, \\ Udine, Italy
}

\begin{abstract}
The objective of this study was to assess complexity of patients discharged from hospital to intermediate care facility in an Italian setting. Multiple anonymous health-related databases were linked through a stochastic key at individual patient level, in order to study patients discharged from the University Hospital of Udine, Italy, between 2010 and 2019. Patient complexity was measured through diagnosis-related group (DRG) relative weight of each hospitalization, number of chronic conditions and annual use of health resources. 12,674 intermediate care facility admissions were recorded in the study period. Mean DRG weight was $1.54 \pm 1.05$ with variations depending on the discharging hospital ward. Patients discharged to intermediate facilities had higher DRG weight, had more comorbidities and consumed more health resources than the others, particularly in case of patients discharged from surgical wards. Patients discharged to intermediate care facilities are particularly complex, make extensive use of health resources, and may be difficult to manage.
\end{abstract}

Correspondence: Francesca Valent, SOC Istituto di Igiene ed Epidemiologia Clinica, Azienda Sanitaria Universitaria Integrata di Udine, via Colugna 50, 33100 Udine, Italy. Tel.: +39.0432.559158.

E-mail: francesca.valent@asufc.sanita.fvg.it

Key words: Intermediate care facilities; diagnosis-related group weight; comorbidity; resource utilization band; Italy.

Contributions: FV designed the study, analyzed and interpreted data and wrote the manuscript; AP conceived the study, contributed to study design, interpreted data and critically reviewed the manuscript. Both authors approved the final version of the manuscript.

Conflicts of interests: the authors declare no potential conflict of interests.

Received for publication: 7 January 2020.

Revision received: 21 February 2020.

Accepted for publication: 27 February 2020.

This work is licensed under a Creative Commons Attribution NonCommercial 4.0 License (CC BY-NC 4.0).

${ }^{\circ}$ Copyright: the Author(s), 2020

Licensee PAGEPress, Italy

Italian Journal of Medicine 2020; 14:55-61

doi:10.4081/itjm.2020.1255 not receive it at outpatient clinics or at home. The profile and role of intermediate care facilities have changed over time ${ }^{1}$ and today they are intermediate facilities between hospital and territory. To ensure the continuity of care to patients discharged from hospitals, procedures aiming at organizing the transition of patients to facilities offering lower intensity of care can be applied. Access to intermediate care facilities occurs after a multidimensional assessment of the patient.

In the Italian Region Friuli Venezia Giulia (FVG), intermediate care facilities are managed by the local health districts; they are rehabilitation-oriented residential facilities, providing continuous care (with high content of healthcare) to patients who are temporarily or permanently disabled and who can be classified, according to the resolution of the regional council D.G.R. No. 1487 of 2000, into three types: i) with physical problems needing continuity of care; ii) with social or social and health problems; iii) with global problems needing high-intensity healthcare outside of the hospital. They are free of charge for the first 30 days for the basic care level and 40 days for rehabilitation. ${ }^{2}$

The local health agency Azienda Sanitaria Universitaria di Udine (ASUIUD) in the FVG Region includes three health districts serving an overall population of approximately 250,000 inhabitants in 37 municipalities, one 1000-bed academic hospital, and 5 intermediate care facilities (one is a hospice dedicated to terminally ill patients). The inhabitants of those 37 municipalities, however, may be also admitted to other intermediate care facilities of the Region.

In FVG, no clinical information or indicators of complexity of patients are recorded in the intermediate care facility electronic administrative databases: pa- 
tients are only categorized according to generic types of problems [e.g., orthopedic, heart, palliative care, dementia, compensated diabetes, diabetic with renal failure, alcohol abuse, chronic obstructive pulmonary disease (COPD), psychiatric, etc.] and demographic data. Thus, it is impossible to assess the level of complexity of patients only looking at data regarding the intermediate care facility episode of care. Nonetheless, information on complexity would be useful for improving the organization of services, which should take into account not only the number of patients but also their care needs.

Limited data exist in Italy on the characterization of patients admitted to intermediate care facilities. ${ }^{3,4}$ Thus, we decided to conduct this study to quantify the level of complexity of patients discharged to intermediate care facilities from the Hospital of Udine, to assess whether such level of complexity has changed over time, and whether the average complexity of patients discharged to intermediate care facilities is different from that of all patients discharged from the Hospital.

\section{Materials and Methods}

The source of information used in this study included various administrative health databases of ASUIUD: we analyzed the intermediate care facility database, the hospital discharge database, and the database of all residents in the municipalities served by the health districts of ASUIUD. These databases are made available for epidemiological analyses as completely anonymous data within a Regional Epidemiological Repository and can be linked with each other at individual patient level through an anonymous stochastic key which is univocal for each subject in all databases.

We used data from January $1^{\text {st }}, 2010$ to June $30^{\text {th }}$, 2019 (the most recent date with complete information at the time of analysis). The analyses regarded only patients living in the 37 municipalities of ASUIUD.

To assess the level of complexity of nursing home patients, we linked to each intermediate care facility admission the hospital discharge, if any, which occurred on the same date or on the day before. Admissions to intermediate care facilities with no previous hospital discharge were considered as having a relief function and excluded from further analyses. We also excluded patients discharged from hospitals other than the Hospital of Udine.

We attached the diagnosis-related group (DRG) relative weight calculated in the hospitalization to all patients who were discharged from the Hospital of Udine. The DRG relative weight, which represents the average resources required to care, for cases in that particular DRG, relative to the average resources used to treat cases in all DRGs, can be considered a proxy indicator of the complexity of the hospitalization, assuming that increased clinical complexity leads to increased use of resources. ${ }^{5}$

We calculated the mean DRG weight for intermediate care facility patients, also stratified by calendar year and discipline of the discharging hospital ward according to the classification by the Italian Ministry of Health. ${ }^{6}$ We compared the average DRG weights of patients discharged to intermediate care facilities with the average among all patients discharged from the hospital wards in the same disciplines. We also assessed whether there was a correlation between DRG weight and intermediate care facility length of stay, to understand whether the complexity of the previous high-intensity-of-care hospitalization affected the length of stay in a facility with lower intensity of care.

Then, only for the year 2018, as additional estimates of patient complexity, we classified intermediate care facility patients according to: i) number of chronic conditions (from a list of 14: patient with transplanted organ, psychiatric disease, rare disease, disease of lipid metabolism, endocrine disease, autoimmune disease, neurologic disease, gastroenteric disease, COPD, cardiovascular disease, diabetes mellitus, cancer, HIV, chronic renal failure), according to algorithms by the Italian Local Health Unit of Brescia; ${ }^{7}$ and ii) resource utilization bands (RUBs) obtained from the aggregation of adjusted clinical groups (ACG), which identify health problems with similar care impact, with the same expected consumption of resources (not only economic) through the Johns Hopkins ACG ${ }^{\circledR}$ System (Johns Hopkins ACG ${ }^{\circledR}$ v.2.11.1). According to this system, the population under study can be divided into 6 possible levels: 0 - no diagnosis, no resource use; 1 - healthy user; 2 - low resource use; 3 - moderate resource use; 4 - high resource use; 5 very high resource use.

Data management and statistical analyses were conducted using SAS v 9.4 (SAS Institute Inc., Cary, NC, USA).

\section{Ethical considerations}

All procedures contributing to this work comply with the ethical standards of the relevant national and institutional committees on human experimentation and with the Declaration of Helsinki. All the analyses were based on anonymous administrative data, therefore patient informed consent and Ethical Committee approval were not required in Italy.

\section{Results}

Between January $1^{\text {st }}, 2010$ and June $30^{\text {th }}, 2019$, 18,244 admissions to intermediate care facilities were recorded among the population of the 37 municipali- 
ties of ASUIUD; of them, $72 \%$ were healthcare oriented (not for giving relief to families). The overall number of admissions to intermediate care facilities increased steadily in the study period, from approximately 1700 in 2010 to $>2000$ per year after 2015 . On the other hand, the proportion of admissions for healthcare purposes did not show a clear trend.

In the 12,674 admissions to intermediate care facilities with healthcare purposes, mean age of patients was $79.5 \pm 10.5$ years (median $81 ; 5^{\circ}$ percentile 59 ; minimum 18), with virtually no changes in time (data not shown). Overall, $60.5 \%$ of patients were females. The proportion of females decreased progressively from $63 \%$ in $2010-2011$ to $57 \%$ in $2018-2019$. Mean DRG weight of the hospitalizations preceding the 12,674 admissions to intermediate care facilities was $1.54 \pm 1.05$.

Table 1 shows admissions to intermediate care fa-

Table 1. Frequency and complexity of patients discharged to intermediate care facilities and of all patients discharged from the Hospital of Udine, Italy, by discharging ward discipline (only for disciplines with $>\mathbf{5}$ patients discharged to intermediate care facilities in the study period), 1/1/2010-30/6/2019.

\begin{tabular}{|c|c|c|c|c|c|c|c|c|c|c|}
\hline \multirow[b]{2}{*}{ Discipline } & \multicolumn{5}{|c|}{ All discharged patients } & \multicolumn{5}{|c|}{ Patients discharged to intermediate care facilities } \\
\hline & No. & $\begin{array}{c}\text { Mean } \\
\text { DRG } \\
\text { weight }\end{array}$ & $\begin{array}{l}\text { Standard } \\
\text { deviation }\end{array}$ & $\begin{array}{l}\text { Mean } \\
\text { length } \\
\text { of stay }\end{array}$ & $\begin{array}{l}\text { Standard } \\
\text { deviation }\end{array}$ & No. & $\begin{array}{l}\text { Mean } \\
\text { DRG } \\
\text { weight }\end{array}$ & $\begin{array}{l}\text { Standard } \\
\text { deviation }\end{array}$ & $\begin{array}{l}\text { Mean } \\
\text { length } \\
\text { of stay }\end{array}$ & $\begin{array}{l}\text { Standard } \\
\text { deviation }\end{array}$ \\
\hline Cardiac surgery & 2,786 & 4.03 & 2.43 & 22 & 20.6 & 181 & 4.99 & 1.47 & 37 & 22.9 \\
\hline Cardiology & 7,692 & 1.69 & 1.21 & 6 & 7.3 & 30 & 2.17 & 1.49 & 27 & 19.9 \\
\hline General surgery & 27,787 & 1.10 & 0.82 & 6 & 7.9 & 554 & 2.04 & 1.30 & 24 & 18.6 \\
\hline Maxillofacial surgery & 3,986 & 1.05 & 0.52 & 3 & 3.4 & 7 & 2.14 & 1.39 & 18 & 16.5 \\
\hline Plastic surgery & 6,081 & 1.06 & 0.37 & 4 & 15.4 & 42 & 1.35 & 0.68 & 24 & 16.8 \\
\hline Thoracic surgery & 740 & 1.99 & 0.73 & 7 & 8.5 & 12 & 1.64 & 0.82 & 23 & 25.8 \\
\hline Vascular surgery & 3,693 & 1.66 & 0.78 & 8 & 9.8 & 204 & 2.43 & 0.81 & 25 & 16.2 \\
\hline Hematology & 3,212 & 2.75 & 3.62 & 21 & 15.6 & 25 & 4.63 & 4.98 & 37 & 21.2 \\
\hline Infectious diseases & 2,091 & 1.47 & 1.05 & 13 & 13.4 & 67 & 2.67 & 1.49 & 40 & 21.5 \\
\hline General medicine & 65,630 & 1.02 & 0.58 & 9 & 18.8 & 4,107 & 1.14 & 0.76 & 18 & 13.0 \\
\hline Spinal unit & 1,415 & 1.52 & 1.13 & 28 & 59.0 & 102 & 1.28 & 1.00 & 22 & 21.3 \\
\hline Nephrology & 2,265 & 1.48 & 1.68 & 17 & 18.5 & 64 & 1.57 & 0.73 & 45 & 28.0 \\
\hline Neurosurgery & 2,737 & 1.98 & 1.26 & 9 & 9.1 & 274 & 2.26 & 1.22 & 18 & 9.7 \\
\hline Neurology & 7,433 & 1.11 & 0.71 & 10 & 8.8 & 639 & 1.30 & 0.58 & 20 & 10.9 \\
\hline Ophthalmology & 4,682 & 0.75 & 0.19 & 4 & 3.6 & 8 & 0.89 & 0.38 & 11 & 5.1 \\
\hline Orthopedics & 15,308 & 1.38 & 0.60 & 8 & 7.8 & 2,812 & 1.87 & 0.46 & 15 & 6.7 \\
\hline Obstetrics and gynecology & 24,232 & 0.60 & 0.28 & 4 & 3.9 & 30 & 1.35 & 0.57 & 25 & 19.8 \\
\hline Ear, nose, and throat & 6,633 & 0.89 & 0.73 & 4 & 6.7 & 52 & 3.35 & 2.27 & 31 & 23.6 \\
\hline Psychiatry & 1,755 & 0.68 & 0.16 & 17 & 41.0 & 29 & 0.73 & 0.11 & 20 & 10.5 \\
\hline Urology & 7,687 & 1.05 & 0.65 & 4 & 4.6 & 64 & 1.80 & 1.21 & 18 & 13.4 \\
\hline Casualty department & 1,611 & 1.06 & 0.54 & 3 & 4.6 & 8 & 1.27 & 0.44 & 8 & 8.7 \\
\hline Functional rehabilitation & 1,201 & 1.04 & 0.47 & 78 & 172.4 & 54 & 1.10 & 0.39 & 125 & 238.6 \\
\hline Gastroenterology & 2,675 & 1.04 & 0.78 & 4 & 4.4 & 13 & 1.41 & 1.01 & 14 & 7.8 \\
\hline Long-term care & 4,310 & 1.09 & 0.63 & 25 & 15.9 & 1,058 & 1.07 & 0.57 & 25 & 15.0 \\
\hline Oncology & 8,985 & 0.91 & 0.50 & 16 & 14.8 & 444 & 1.10 & 0.85 & 21 & 13.6 \\
\hline Pneumology & 6,282 & 1.47 & 1.10 & 13 & 13.9 & 285 & 2.09 & 2.03 & 34 & 24.8 \\
\hline Rheumatology & 1,747 & 0.92 & 0.30 & 13 & 11.3 & 17 & 1.32 & 0.64 & 43 & 32.1 \\
\hline Oncologic radiotherapy & 838 & 0.85 & 0.33 & 17 & 14.7 & 20 & 1.61 & 1.39 & 25 & 17.0 \\
\hline Neuro-rehabilitation & 441 & 1.04 & 0.34 & 52 & 58.9 & 29 & 1.19 & 0.51 & 53 & 38.7 \\
\hline
\end{tabular}


cilities stratified by discipline of the discharging hospital ward (only for disciplines with $>5$ discharges to intermediate care facilities in the study period), and the overall hospital discharges from the same disciplines, with mean DRG weights and length of hospital stay. Overall, among patients hospitalized at the Hospital of Udine, mean weight was higher among patients who died in hospital $(1.49 \pm 1.34)$ than among the

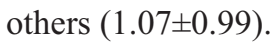

Disciplines discharging the highest numbers of patients to intermediate care facilities were general medicine ( $>4000$ discharges overall), orthopedics (almost $3000)$ and long-term care $(>1000)$, followed by neurology, general surgery, and oncology (approximately 500 each). Disciplines discharging the highest proportions of patients to intermediate care facilities were long-term care (almost 25\%), orthopedics (almost 20\%), neurosurgery $(10 \%)$, neurology, spinal unit, neuro-rehabilitation, cardiac surgery, and general medicine (6-9\%). The highest mean DRG weight, both for patients discharged to intermediate care facilities and overall, was in cardiac surgery ( $>4)$. In almost all disciplines, mean DRG weight in the subgroup of patients discharged to nursing homes was higher than in the overall group. Similarly, mean length of stay was generally longer in patients discharged to intermediate care facilities.

In the study period, in almost all disciplines, mean DRG weight of patients discharged to intermediate care facilities remained approximately constant, except in neurology, where the weight increased from 1.16 to 1.45 (annual number of patients discharged to intermediate care facilities: 50-90).

Overall, the length of intermediate care facility stay was on average $27 \pm 27$ days, with no relevant changes over time (data not shown). Among 1,678 patients who died in the intermediate care facility $(9.2 \%)$, the observed mean length of stay was shorter ( $20 \pm 29$ days). The proportion of patients who died in the intermediate care facility varied depending on the discharging hospital discipline, the highest values being in oncology (242 patients, $54.0 \%$ ), ear, nose and throat (15 patients, $27.3 \%$ ), urology (16 patients, $22.9 \%$ ), general medicine (1004 patients, $21.1 \%$ ). No deaths in intermediate care facility were observed for patients discharged from cardiac surgery, cardiology, maxillofacial surgery, dermatology, ophthalmology. After excluding deaths, we found a minimal inverse correlation between mean DRG weight of the preceding hospitalization and length of intermediate care facility stay $(r=-0.034, P=0.0003)$. Stratifying by discharging discipline, we observed a negative correlation for patients discharged from cardiac surgery $(\mathrm{r}=$ $-0.204, \mathrm{P}=0.0058)$ and orthopedics $(\mathrm{r}=-0.071$, $\mathrm{P}<0.0001)$ and a positive correlation for those discharged from general surgery $(\mathrm{r}=0.132, \mathrm{P}=0.0018)$ and gastroenterology $(\mathrm{r}=0.823, \mathrm{P}=0.0034)$.
The population discharged to intermediate care facilities in $2018(\mathrm{~N}=1,446)$ made an extensive use of health resources during the same year: very high in $29.7 \%$ of patients, high in $32.7 \%$, moderate in $32.1 \%$, low in $5.5 \%$. Stratifying the analysis by hospital discharge discipline (only in case of $\geq 10$ discharges to nursing home in the year), great differences were observed among different disciplines and between patients discharged to intermediate care facilities and all discharged patients (Figure 1).

Of patients discharged to intermediate care facilities, only $2 \%$ did not have any chronic condition according to our algorithms; $31 \%$ had $1-2$ conditions, $23 \%$ had $3-4$, the remaining $20 \%$ had $\geq 5$. Table 2 shows the average number of comorbidities among all patients discharged from the hospital and in the subgroup discharged to intermediate care facilities by discharging discipline (for disciplines with $\geq 10$ discharges to intermediate care facilities in 2018). In surgical disciplines, the average number of comorbidities was higher in the subgroup of patients discharged to intermediate care facilities.

\section{Discussion}

This study provides a picture of patients discharged to intermediate care facilities for healthcare purposes in the Italian area of Udine, describing not only the discharging wards but also the complexity of patients. Some findings are not new in Italy. For example, a report from the Institute for economic and social research Morosini described the typical intermediate care facility patient as having an average age $>80$, mostly female, multi-pathological (4 diseases), in polypharmacy, with light cognitive deficit. ${ }^{3}$ In our area, mean age was approximately 80 , although there were also younger patients. We confirm that patients were usually affected by multiple comorbidities ( 3 or more). In addition, we show that, particularly in surgical patients, the average number of comorbidities among those discharged to intermediate care facilities was higher than among all patients discharged from the hospital. Among intermediate care facility patients, females outnumbered males, although their relative frequency has decreased over time. Another Italian study described patients hospitalized in a particular type of intermediate care facility, i.e., Community Hospital, in the Region Emilia-Romagna. ${ }^{4}$ They are also elderly people (mean age 79.5), mostly female and with more than one health condition in $75 \%$ of cases, being hypertension, depression, anxiety, diabetes, and cerebrovascular diseases the most frequent conditions. $^{4}$

The most original findings of our study regard the assessment of patient complexity through mean DRG weight and the estimate of consumption of health re- 


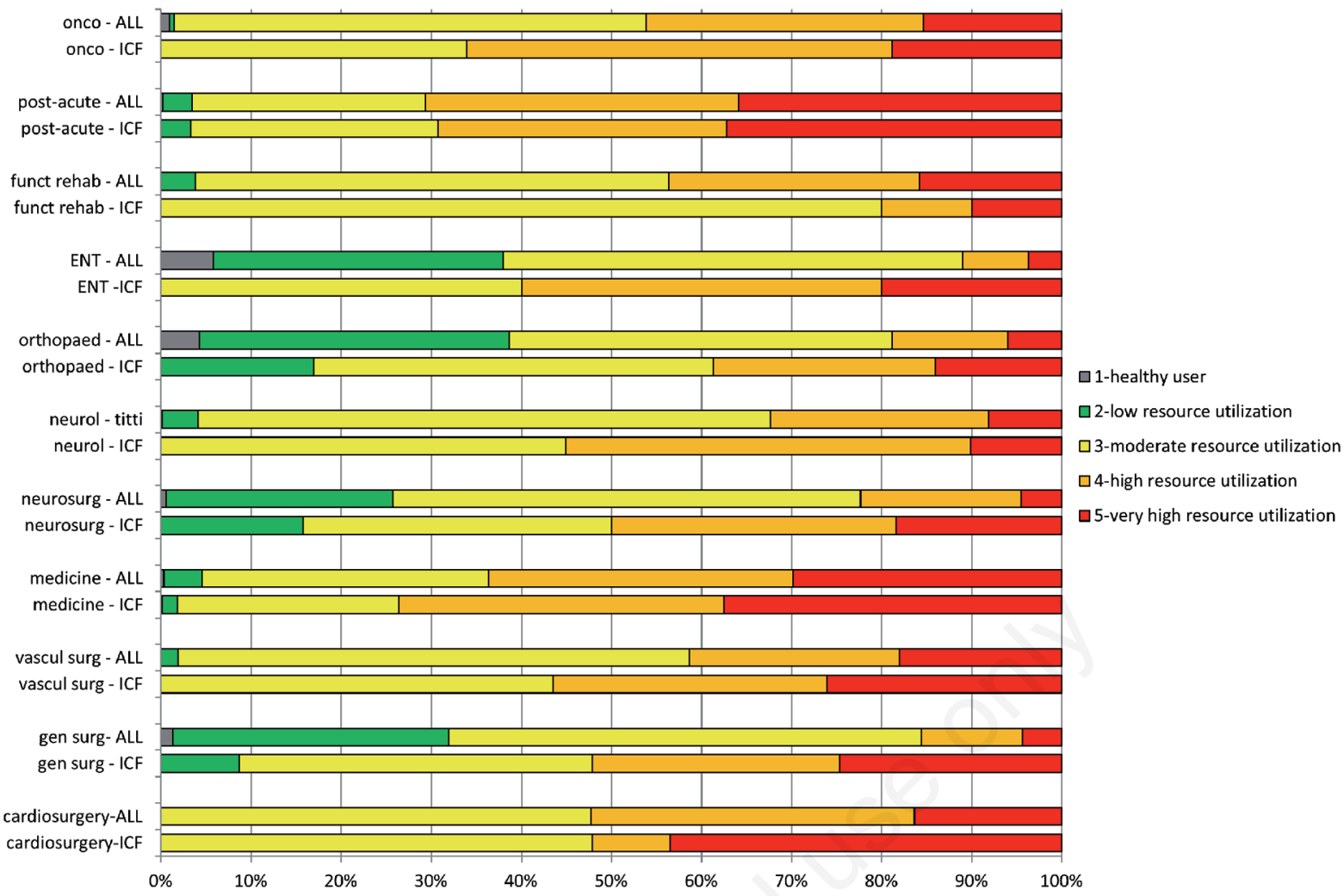

Figure 1. Resource utilization bands (RUB) for overall patients discharged from the University Hospital of Udine in 2018 and for those discharged to intermediate care facilities by discipline of the discharging hospital ward (disciplines with $\geq 10$ patients discharged to intermediate care facilities in 2018). ICF, intermediate care facility.

Table 2. Mean number of chronic conditions among patients discharged from the University Hospital of Udine, Italy, by discharging ward discipline (for disciplines with $\geq 10$ patients discharged to intermediate care facilities in 2018 ).

\begin{tabular}{|c|c|c|c|c|c|}
\hline \multirow[b]{2}{*}{$\begin{array}{l}\text { Discipline of hospital } \\
\text { discharging ward }\end{array}$} & \multirow[b]{2}{*}{$\begin{array}{c}\text { No. patient } \\
\text { discharged to } \\
\text { intermediate care } \\
\text { facilities }\end{array}$} & \multicolumn{2}{|c|}{ All discharged patients } & \multicolumn{2}{|c|}{ Patients discharged to intermediate care facilities } \\
\hline & & $\begin{array}{l}\text { Mean number } \\
\text { of chronic } \\
\text { conditions }\end{array}$ & $\begin{array}{l}\text { Standard } \\
\text { deviation }\end{array}$ & $\begin{array}{l}\text { Mean number } \\
\text { of chronic } \\
\text { conditions }\end{array}$ & $\begin{array}{l}\text { Standard } \\
\text { deviation }\end{array}$ \\
\hline Cardiac surgery & 23 & 3.8 & 1.5 & 4.3 & 1.4 \\
\hline General surgery & 70 & 1.8 & 1.6 & 2.9 & 1.5 \\
\hline Vascular surgery & 23 & 3.6 & 1.4 & 3.1 & 1.3 \\
\hline Long-term care & 154 & 3.2 & 1.5 & 3.1 & 1.5 \\
\hline General medicine & 625 & 3.4 & 1.6 & 3.4 & 1.5 \\
\hline Neurosurgery & 38 & 2.1 & 1.6 & 3.2 & 1.5 \\
\hline Neurology & 70 & 2.7 & 1.6 & 3.2 & 1.5 \\
\hline Oncology & 53 & 3.2 & 1.4 & 3.3 & 1.5 \\
\hline Orthopedics & 284 & 1.9 & 1.6 & 2.9 & 1.5 \\
\hline Ear, nose, and throat & 10 & 1.6 & 1.7 & 3.1 & 1.4 \\
\hline Pneumology & 32 & 3.0 & 1.7 & 3.6 & 1.7 \\
\hline Functional rehabilitation & 10 & 2.9 & 1.4 & 3.5 & 1.7 \\
\hline
\end{tabular}


sources. Mean DRG weight of the previous hospital stay did not change substantially during the study period. It was higher than the average weight of all patients discharged from the same wards, despite the fact that the latter included patients who died in hospital (with higher DRG weights). In a way, this is expected, since the least complex cases, with no need of highintensity care, are discharged home. Nonetheless, our finding is important because it underlines the fact that patients arriving at intermediate care facilities may be very difficult to manage.

Comparisons with international studies are difficult, mainly because there is no agreement in the definition of intermediate care. ${ }^{8}$ In fact, depending on the source, this term may refer to services favoring the transition from hospital to home, or to services that require less resources of an acute care hospital but are not primary care, or to something closer to nursing homes. ${ }^{8}$ Keeping these differences in mind, various studies characterized patients who are provided with intermediate care. A U.S. study showed that among Intensive Care Unit (ICU) patients, those with lower socioeconomic status (SES) have higher probability of being discharged to nursing homes. ${ }^{9}$ We did not have SES information and could not assess the impact of SES on discharge disposition.

A study on hepatopancreatic surgical patients found that patients discharged to a skilled nursing facility or intermediate care facility were older and had more comorbidities and more functional loss than those discharged home. ${ }^{10}$ Another U.S. study identified older age, length of ICU stay, injury severity, number of comorbidities as factors predicting discharge to nursing homes among patients hospitalized after a fall. ${ }^{11}$ According to the Authors, since those factors can be assessed at the beginning of the hospital stay, their knowledge may help planning the discharge and reducing length of stay.

Another study from the U.S. found that, in a population of hospitalized patients $\geq 70$ years of age, the Hospital Admission Risk Profile score which can be easily calculated during a patient admission process from age, cognitive status and self-reported instrumental activities of daily living, strongly predicts the risk of discharge to a skilled nursing or rehabilitation facility. ${ }^{12}$ In our area, too, the early assessment of comorbidities contributes to the decisions leading to patient referral to nursing homes or intermediate care facilities, as well as the family and social care context and the severity of the acute condition that caused the hospitalization.

A particularly interesting finding of our study regards the consumption of health resources. In 2018, $60 \%$ of intermediate care facility patients made a very high or high use of resources: in the general population, the proportion of subjects with such a high re- source use is incomparably lower (the Italian Veneto Region estimates they are approximately $4 \%{ }^{13}$ ). It is true, and obvious, that the overall hospitalized patient population has a high consumption of resources; nonetheless, those who are discharged to intermediate care facilities, from the same hospital wards, consume more. The difference in resource use between patients discharged to intermediate care facilities and all discharged patients is more evident for surgical patients. A recent study from the U.S., comparing patient outcomes and costs between patients receiving post-acute care at home and those receiving care in a skilled nursing facility showed that discharge home with home care, although less costly, was associated with higher 30-day readmission rate. ${ }^{14}$ Thus, intermediate care may play a relevant role also in our context to improve outcomes in this complex population which requires high health resource use.

In the U.S., staff- and equipment-related barriers to transitioning obese patients from hospital to nursing home have been identified. ${ }^{15,16}$ Barriers analogous to those described for obese patients may be also found for other types of complex patients; we cannot exclude that in our area there have been problems due to either structural issues or staffing shortage upon admission of patients with particular conditions.

Discharge destination may also affect hospital length of stay. In fact, in a study of patients with traumatic brain injury, those with a discharge disposition to rehabilitation facilities, skilled nursing facilities, and intermediate care facilities were more likely to experience a discharge delay than those discharged home, possibly because of a lack of available beds at the discharge destination. ${ }^{17}$ Therefore, it is important that patients who are eligible to be discharged to an intermediate care facility are carefully selected to avoid overcrowding.

Once a patient is admitted to an intermediate care facility, length of stay is not influenced by the complexity of the previous hospitalization. Length of stay in the intermediate care facility, on average 27 days, might be seen as the time a patient needs to regain autonomy or to be able to continue treatment at home. This is consistent with the FVG regional guidelines on intermediate care facility ${ }^{2}$ which state that the usual stay should not exceed 30 days for the basic care level and 40 days for rehabilitation. For cardiosurgical and orthopedic patients, length of stay was even inversely related to complexity of the previous hospitalization (generally very high): in those cases, the use of resources in hospital could be caused by the complexity of the surgical procedures, but the same resource use may not be required in the admitting intermediate care facility where the recovery of autonomy may be fast. Among these patients, also, there are no deaths in intermediate care facilities. 


\section{Conclusions}

In conclusion, this study showed for the first time in an Italian context that patients discharged from hospital to intermediate care facility are mostly very old, have multiple comorbidities, come from long and complex hospitalizations, and make an extremely high use of health resources. Their management in intermediate care facilities may be challenging.

\section{References}

1. Banchero A, Bozzo G, Malagamba E. Il monitoraggio della qualità dell'assistenza in RSA. I quad-erni dell'Agenzia. Regione Liguria. Genova, 2013. Available from: http://www.alisa.liguria.it/index.php?option=com_docman\&task=doc_download\&gid=923\&Itemid $=184$. Accessed: November 29, 2019.

2. Regione autonoma Friuli Venezia Giulia. Linee guida per la gestione delle Residenze Sanitarie As-sistenziali. Allegato alla Delibera N. 2151 del 29 ottobre 2015. Available from: http://mtom.regione.fvg.it/storage/ 2015_2151/Allegato\%201\%20alla\%20Delibera\%20215 1-2015.pdf. Accessed: November 29, 2019.

3. Montemurro F, Petrella A. Le politiche per gli anziani non autosufficienti nelle regioni italiane. To-rino, 2016. Available from: http:/www.sossanita.it/doc/2016_10_ Rapporto-SPI-NA-rsa.pdf. Accessed: November 29, 2019.

4. Pianori D, Avaldi VM, Rosa S, et al. How do Community Hospitals respond to the healthcare needs of elderly patients? A population-based observational study in the Emilia-Romagna Region. Ann Ig 2018;30:317-29.

5. Ministero della Salute. Glossario. Peso relativo. August 31, 2015. Available from: http://www.salute.gov.it/portale/temi/p2_6.jsp?lingua $=$ italiano\&id=3669\&area=ricoveriOspedalieri\&menu=vuoto. Accessed: November 29, 2019.

6. Ministero della Salute. Allegato 1 alla Dati di struttura e di organizzazione della unità sanitaria lo-cale. Supplemento ordinario alla Gazzetta Ufficiale. 27/01/2007. Available from: http://www.trovanorme.salute.gov.it/ norme/renderPdf.spring? seriegu $=\mathrm{SG} \&$ datagu $=27 / 01 / 20$ 07\&redaz $=07 \mathrm{~A} 00580 \&$ artp $=1 \&$ art $=1 \&$ subart $=1 \&$ subart $1=10 \&$ vers $=1 \& \operatorname{prog}=01$. Accessed: November 29 , 2019.

7. ASL di Brescia in «La presa in carico dei malati cronici nell'ASL di Brescia: monitoraggio BDA 2013». Available from: https://www.ats-bre-scia.it/media/documenti/cure_primarie/anno\%202013/Medici $\% 20$ Cure $\% 2$ 0Primarie/Strumenti\%20Professionali/Malati\%20cronic
i\%20e\%20PDT\%20-\%20monitoraggio/BDA2012_Finale esteso.pdf. Accessed: November 29, 2019.

8. Barwise A, Juhn YJ, Wi CI, et al. An Individual Housing-Based Socioeconomic Status Measure Predicts Advance Care Planning and Nursing Home Utilization. Am J Hosp Palliat Care 2019;36:362-9.

9. Melis RJF, Olde Rikkert MGM, van Eijken MIJ. What is intermediate care? An international con-sensus on what constitutes intermediate care is needed. BMJ 2004;329:360-1.

10. Paredes AZ, Hyer JM, Tsilimigras DI, et al. Predictors and outcomes of nonroutine discharge after hepatopancreatic surgery. Surgery 2019;165:1128-35.

11. James MK, Robitsek RJ, Saghir SM, et al. Clinical and non-clinical factors that predict discharge disposition after a fall. Injury 2018;49:975-82.

12. Liu SK, Montgomery J, Yan Y, et al. Association Between Hospital Admission Risk Profile Score and Skilled Nursing or Acute Rehabilitation Facility Discharges in Hospitalized Older Adults. J Am Geriatr Soc 2016;64:2095-100.

13. Corti MC. Relazione finale sulle attività progettuali del secondo anno di sperimentazione del siste-ma ACG - Adjusted Clinical Groups. April 10, 2014. Available from: https://21053b62-a-25ee4ffc-s-sites.googlegroups. $\mathrm{com} / \mathrm{a} / \mathrm{regione}$.veneto.it/acg/risultati-preliminari/FinalReport-2013/FinalReport_ACG_2013.pdf? attachauth=ANoY7conF3xoDzDD5WsoOn_dmfFnt67r WCgYKsHEvpgSsAbLp-kT5PNi3yÜAj_X9AvPVFgv6frttrpLmGtkF6Qc1FWKUMsXxhagsmohjr47 VQh5g2tcE8 1G3HeMHbjMfHOA3msezAJ f7rP0sUvlxbediONgQQ2kSaAikvUNWXqqgltvuF3VWT2Z59y gZ1kVjrecqZzku6prSTHWA-YCn7BnaQkHNPAZMWP_wVxxC2m0ht1EiT6FrJ-WKZcXbYnUU2 wsiux 736tA 45 hQcHX265Gh2zYG_Vw\%3D\%3D\&attredirects $=0$. Accessed: November 29, 2019.

14. Werner RM, Coe NB, Qi M, Konetzka RT. Patient Outcomes After Hospital Discharge to Home With Home Health Care vs to a Skilled Nursing Facility. JAMA Intern Med 2019;179:617-23.

15. Felix HC, Bradway C, Ali MM, Li X. Nursing Home Perspectives on the Admission of Morbidly Obese Patients From Hospitals to Nursing Homes. J Appl Gerontol 2016;35:286-302.

16. Bradway C, Felix HC, Whitfield T, Li X. Barriers in Transitioning Patients With Severe Obesity From Hospitals to Nursing Homes. West J Nurs Res 2017;39: 1151-68.

17. Sorensen M, Sercy E, Salottolo K, et al. The effect of discharge destination and primary insurance provider on hospital discharge delays among patients with traumatic brain injury: a multicenter study of 1,543 patients. $\mathrm{Pa}-$ tient Saf Surg 2020;14:2. 